

\section{Sumário}

A DISCRIMINAÇÃo RACIAL NO BRASIL E A ASCENSÃo DO POVO NEGRO: UM OLHAR A PARTIR DOS PRINCÍPIOS CONSTITUCIONAIS NA LUTA PELA CIDADANIA INCLUSIVA

Bruno Mello Correa de Barros e Rita Mara Albrecht

As MULHERES NO CONTEXTO DA SOCIEDADE DE CLASSES E SUA PARTICIPAÇÃO POLÍTICA NO PROCESSO LEGISLATIVO E EXECUTIVO DO BRASIL: RESTRIÇÕES E DESAFIOS

Rafael Bueno da Rosa Moreira e Marli Marlene Morais da Costa

FACTORES ASOCIADOS A LA VIOLENCIA DE GÉNERo EN PAREJAS ADOLESCENTES

Maria del Carmen Monreal Gimeno

Os IMPACTOS DAS TECNOLOGIAS DA INFORMAÇÃO NO FLUXO DE PESSOAS: VIOLAÇÕES DA LIBERDADE EM UM MUNDO SECURITIZADO

Elias Jacob de Menezes Neto, Jose Luis Bolzan de Morais e Victoria Layze Silva Fausto

El DELITO DE ENALTECIMIENTO TERRORISTA. ¿INSTRUMENTO DE LUCHA CONTRA EL PELIGROSO DISCURSO DEL ODIO TERRORISTA O MECANISMO REPRESOR DE REPUDIABLES MENSAJES DE RAPEROS, TWITTEROS Y TITIRITEROS?

Alfonso Galán Muñoz

As POLÍtiCAS PÚBLICAS E A PROMOÇão DA DIGNIDADE: UMA ABORDAGEM NORTEADA PELAS CApacidades (CAPABIlities APproach) propostas por Martha Nussbaum

Anna Paula Bagetti Zeifert e Janaína Machado Sturza

A INFLUÊNCIA DA MÍdia PARA O CONSUMO DE TABACO

Luís Renato Vedovato e Maria Carolina Gervásio Angelini

¿SON PARTE DEL BLOQUE DE CONSTITUCIONALIDAD LOS PRINCIPALES TRATADOS internacionales de derechos humanos de la ONU en Chile? Del texto positivo a la APLICACIÓN EN TRIBUNALES DE JUSTICIA Juan Pablo Díaz Fuenzalida

Potestad calificadora del Conservador de Bienes Raíces y Procedimiento Registral ....173 Sebastián Bozzo Hauri e Gonzalo Ruz Lartiga

DESARTICULAÇÃo INTERFEDERATIVA E CONCESSÃo DOS BENEFÍCIOS DE PRESTAÇÃo CONTINUADA (BPC) 
Aprendizagem Profissional e o poder público municipal: proposta de maior eficácia À POLÍTICA PÚBLICA

José Rodrigo Paprotzki Veloso

Direito A Conciliação Entre Trabalho E Família................................................229

Edilton Meireles de Oliveira Santos

Trabajo y diversidad funcional. La situación EN EL ORdenamiento JuRídico español 245 María Esther Carrizosa Prieto

Custos de TransaÇão como uma METAPolítica pública .........................................2276

João Luis Nogueira Matias e Ricardo José Brito Bastos Aguiar de Arruda

REVISITANDO O CONCEITO DE SERVIÇO PÚBLICO

Andre Luiz Dos Santos Nakamura

O Brasil FACE AOS NOVOS PADRÕES DE COMÉRCIO E INVESTIMENTO DOS ACORDOS INTERNACIONAIS

Michelle Sanchez Badin, Fabio Costa Morosini e David M. Trubek

Os contratos comerciais na Declaração dos Direitos de Liberdade Econômica (MP 881/19).

André Lipp Pinto Basto Lupi

O MARCO LEGAL DA INOVAÇÃO E O AUMENTO DA INTERAÇÃO ENTRE UNIVERSIDADE E EMPRESA: CONTRIBUIÇÕES PARA A CONSOLIDAÇÃO DO DIREITO FUNDAMENTAL AO DESENVOLVIMENTO ....352 Thiago Paluma e Eline Débora Teixeira

RELICITAÇÃo DAS CONCESSÕES DE GERAÇÃo DE ENERGIA ELÉTRICA E A REVERSÃo DE BENS....372 Patrícia Regina Pinheiro Sampaio e Sergio Guerra

FinANCIAMENTO TRANSGERACIONAL DA INFRAESTRUTURA VERDE FLORESTAL: O SISTEMA DE PAGAMENTO POR SERVIÇOS AMBIENTAIS COMO INSTRUMENTO DE GESTÃO DE RISCOS NA SOCIEDADE CONTEMPORÂNEA...................................................................................................390

Délton Winter de Carvalho e Kelly de Souza Barbosa

Mediação como Política Pública para Tratamento de Conflitos Consumeristas ..... 415 Fernanda Sartor Meinero e Fernando Pedro Meinero

A ParticipaÇão do AMICUS CURIAE EM DECISÕES JUdiCIAIS E SUA CONSEQUENTE CONTRIBUiÇÃo para efetivação de Políticas Públicas .429

Viviane Nobre Santana 
A ISONOMIA TRIBUTÁRIA COMO LIMITE À TRIBUTAÇÃo E À CONCESSÃO DE ISENÇÕES FISCAIS, E A INEFETIVIDADE DO CONTROLE JURISDICIONAL DESSAS ISENÇÕES..................................450

Paulo Alves da Silva Paiva e Alexandre Augusto Batista de Lima

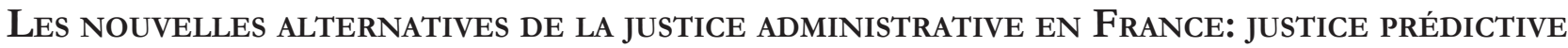
ET JUSTICE AMIABLE

Marie-Odile Diemer

O ESTADO DA LUXÚRIA: A PARÁBOLA DO BMW E A REAL DIMENSÃo DO DEBATE SOBRE A RESERVA DO POSSÍVEL: ESCASSEZ DE RECURSOS OU ORDENAÇÃo DE PRIORIDADES?................................484 Assis José Couto do Nascimento

O PODER CONSTITUINTE

José Levi Mello do Amaral Júnior

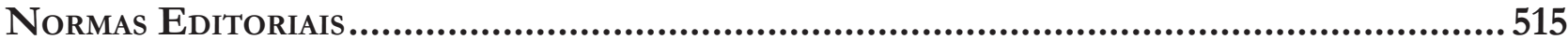

Envio dos trabalhos: 


\title{
¿Son parte del bloque de constitucionalidad los principales tratados internacionales de derechos humanos de la ONU en Chile? Del texto positivo a la aplicación en tribunales de justicia*
}

\author{
Are the main international human rights \\ treaties of the UN in Chile part of the \\ constitutionality block? From the positive text \\ to the application in courts of justice
}

Juan Pablo Díaz Fuenzalida**

\section{Resumen}

El presente trabajo estudia si los principales tratados internacionales de derechos humanos de la ONU son parte del bloque de constitucionalidad en Chile. Para responder a aquella interrogante se sintetizan los principales argumentos doctrinarios para aplicar los tratados sobre derechos humanos en Chile; se analiza la normativa constitucional aplicable en Chile para aplicar los tratados referidos; y, finalmente se comprueba si los tratados citados son utilizados en los máximos tribunales de justicia. Se desarrolla cada punto anterior con doctrina, normativa nacional e internacional y con jurisprudencia de los máximos tribunales de justicia. La investigación cristaliza al evidenciar que desde todos los prismas son aplicables cada uno de los tratados revisados en Chile. Las conclusiones son que los principales tratados sobre derechos de la ONU son parte del bloque de constitucionalidad en Chile, tanto en el texto positivo como en la práctica en los tribunales de justicia, abriendo un abanico de derechos fundamentales para todos los habitantes.

Palabras clave: Bloque de constitucionalidade. Tratados Internacionales sobre Derechos Humanos. Naciones Unidas.

* Guest author / Autor convidada

** Doctor en Derecho, Máster en Gobernanza y Derechos Humanos, ambos por la Universidad Autónoma de Madrid; Magister en Docencia Universitaria, Licenciado en Ciencias Jurídicas y Sociales, ambos por la Universidad Autónoma de Chile; profesor de Derecho Constitucional e investigador adscrito al Instituto de Investigación en Derecho de la Universidad Autónoma de Chile; Editor alterno de la Revista Justicia y Derecho de la Universidad Autónoma de Chile. Dirección postal: Avenida Pedro de Valdivia 425, Providencia, Santiago de Chile. E-mail : juanpablo.diaz@uautonoma.cl.

\section{Abstract}

The present work studies if the main international treaties of human rights of the UN are part of the block of constitutionality in Chile. To answer that question, the main doctrinaire arguments for applying human rights treaties in Chile are synthesized; the constitutional regulations applicable in Chile to apply the aforementioned treaties are analyzed; and, finally, it is verified whether the aforementioned treaties are used in the highest courts of justice. Each previous point is developed with doctrine, national and international regulations and with jurisprudence of the highest courts of justice. The investigation crystallizes when evidencing that all the treaties reviewed in Chile are applicable from all the prisms. The conclusions are that the main treaties on the rights of the UN are part of the constitutionality block 
in Chile, both in the positive text and in practice in the courts of justice, opening a range of fundamental rights for all inhabitants.

Key words: Constitutionality block. International Treaties of Human Rights. United Nations.

\section{Introducción}

Aplicar la Constitución es más que el mero texto normativo aprobado en el 1980 o bien, por el constituyente derivado del 2005 con todas las modificaciones hasta la fecha. Hoy en día se habla de "bloque de constitucionalidad" que contendría una serie de normas relacionadas a la Carta Fundamental. Así, por ejemplo, para el caso colombiano se ha dicho que el bloque de constitucionalidad está conformado no sólo por el articulado de la Constitución, sino que, entre otros, por los tratados internacionales que trata el artículo 93 de la Carta Fundamental, por las leyes orgánicas y, en algunas ocasiones, por las leyes estatutarias.

Sin embargo, cada vez es más difícil tener un manejo de la normativa que debe aplicarse. Dicho fenómeno es un acontecer que Natalino Irti estudió hace cerca de treinta años, pero lamentablemente se ha acrecentado aún más su diagnóstico. Irti en los años 80-90 explicaba como las instituciones de derecho civil italiano se iban expandiendo a otros cuerpos normativos, distintos del Código Civil, siendo la especialidad un factor a considerar para cada caso concreto ${ }^{2}$. Ocurre exactamente lo mismo al dilucidar cuál es el bloque de constitucionalidad, la normativa que hay que considerar no sólo es de ley orgánica que desarrolle a las Cartas Fundamentales, sino que hoy hay que revisar si son o no aplicables una serie de tratados internacionales relacionados con el Derecho Constitucional.

En efecto, entre otras normas relevantes que, podrían ser parte del bloque de constitucionalidad en un país son los principales tratados sobre derechos humanos creados en la ONU. Es de suma importancia establecer si para un país son o no parte de su bloque de constitucionalidad, pues ello abre un abanico de derechos fundamentales para sus habitantes, que, sólo en cuantía (si lo evaluamos desde el número de páginas) a lo menos duplica el catálogo de derechos esenciales para los ciudadanos o bien profundiza en cada uno de ellos. En efecto, para el estudio el presente estudio, se considera entre los principales tratados a los de texto sustantivo (en general, no a los protocolos facultativos que crean o desarrollan instituciones internacionales), en concreto los siguientes tratados sobre derechos humanos de la ONU:

1. La Convención Internacional sobre la Eliminación de todas las Formas de Discriminación Racial.

2. El Pacto Internacional de Derechos Civiles y Políticos.

3. El Pacto Internacional de Derechos Económicos, Sociales y Culturales.

4. La Convención sobre la eliminación de todas las formas de discriminación contra la mujer.

5. La Convención contra la Tortura y Otros Tratos o Penas Crueles, Inhumanos o Degradantes.

6. Convención sobre los Derechos del Niño.

7. Convención internacional sobre la protección de los derechos de todos los trabajadores migratorios y de sus familiares.

8. Convención sobre los derechos de las personas con discapacidad.

9. Convención internacional para la protección de todas las personas contra las desapariciones forzadas.

\footnotetext{
1 MORALES MORALES, Alejandra Virginia. ODIMBA ON’ETAMBALAKO WETSHOKONDA, Jean Cadet. La incorporación del concepto del bloque de constitucionalidad en matéria de derechos humanos en México. Prolegómenos. Derechos y Valores, Bogotá, Colombia, v. 12, n. 27, p. 135-14, enero-jun. 2011.

2 IRTI, Natalino. La edad de la descodificación. España: J. M. Bosch Editor.
} 
Todos ellos se originan remotamente desde el día 10 de diciembre de 1948, en que ocurrió un acontecimiento sin igual, la Asamblea General de Naciones Unidas, reunida en París, en su resolución 217 A (III) aprobó la Declaración Universal de Derechos Humanos. Sólo ocho países se abstuvieron de votar y ninguna nación votó en contra. No siendo obligatoria la resolución, es una verdadera hoja de ruta que marca el camino a seguir en materia de Derechos Humanos ${ }^{3}$. Así, por primera vez las naciones del mundo se ponían de acuerdo en un texto que reconociera los Derechos Fundamentales de las personas ${ }^{4}$. No obstante, como se decía, es una guía en el progreso de las naciones, pero no tiene obligatoriedad como los tratados internacionales anteriormente citados, por ello, la importancia del estudio de estos últimos textos normativos que son vinculantes para los Estados al ser de naturaleza de tratados internaciones.

Así, la presente investigación se plantea como objetivo general de trabajo si son parte del bloque de constitucionalidad los principales ${ }^{5}$ tratados internacionales sobre derechos humanos de la ONU en el Estado de Chile. Para ello, es menester determinar objetivos específicos que tributen al objetivo general. Estos objetivos particulares son:

1. Sintetizar los principales argumentos doctrinarios para aplicar los tratados sobre derechos humanos en Chile.

2. Determinar la normativa constitucional aplicable en Chile para aplicar los tratados referidos.

3. Comprobar que los tratados citados son aplicables en los máximos tribunales de justicia en Chile.

Así, metodológicamente se evidenciará con doctrina, normativa y jurisprudencia relacionada a cada uno de los objetivos específicos. Con el desarrollo de cada uno se podrá responder claramente si los tratados internacionales sobre derechos humanos de la ONU son o no parte del bloque de constitucionalidad en Chile.

\section{Argumentos doctrinarios y normativos para incluir a los principales tratados sobre derechos humanos de la ONU en el bloque de constitucionalidad chileno}

En el año 1989 se realiza una reforma constitucional en Chile que modifica el inciso segundo del artículo 5 de la Carta Fundamental. En efecto, en su antigua redacción, se consagraba que el ejercicio de la soberanía reconoce como limitación el respeto a los derechos esenciales que emanan de la naturaleza humana. Ello traía complejidades en la interpretación ¿Cuáles eran aquellos derechos? Y es así que, en virtud de la Ley de Reforma Constitucional $\mathrm{N}^{\circ}$ 18.825, de 17 de agosto de $1989^{6}$, que se agregó una parte, dando mayor certeza, encuadrando los derechos esenciales de la naturaleza humana en aquellos garantizados por la Constitución, así como por los tratados internacionales ratificados por Chile y que se encuentren vigentes. Hoy, al 2019, dicha redacción sigue intacta.

La redacción de la reforma del año 1989 de la Constitución chilena, tan explicita que hace referencia a los tratados internacionales no era sólo por una necesidad de certeza jurídica, sino que era para su aplicación en Tribunales de Justicia. En tal sentido, nos recuerda el profesor Francisco Cumplido Cereceda que, de

\footnotetext{
3 NACIONES UNIDAS. Historia de la redacción de la Declaración Universal de Derechos Humanos. Disponible en: http:// www.un.org/es/documents/udhr/history.shtml. Disponible em: 25 enero 2019.

4 MARTÍN-RETORTILLO BAQUER, Lorenzo. Una visión de la tutela judicial a partir de la jurisprudencia de la Corte Interamericana y del Tribunal Europeo de Derechos Humanos. En: FERRER MAC GREGOR, Eduardo; HERRERA GARCÍA, Alfonso (coord.). Diálogo jurisprudencial en derechos humanos: entre Tribunales Constitucionales y Cortes Internacionales. 2013. p. 12171260. ( In memoriam Jorge Carpizo, generador incansable de diálogos).

5 Cuando se indica "principales", se hace referencia a los 9 ya citados anteriormente.

6 CHILE. Ley de reforma constitucional No 18.825, de 17 de agosto de 1989. Disponible en: http://www.leychile.cl/Navegar/scripts/ob tienearchivo?id=recursoslegales/10221.3/44169/2/HLArt5CPR.pdf. Disponible en: 22 abr. 2019.
} 
forma esporádica los Juzgados y Cortes aplicaban directamente las normas de la Constitución y, respecto de los tratados exigían frecuentemente una legislación que recepcionara lo convenido ${ }^{7}$. Es decir, una ley que los pusiera de práctica o desarrollo a pesar de ya haber sido ratificados por el país. Y, adiciona el profesor que durante el periodo de 1973 a 1989, como no se había publicado ciertos tratados en el Diario Oficial, los tribunales se excusaban de que no estaban aún vigentes para Chile. ${ }^{8}$ Un ejemplo de esto último son el Pacto de Derechos Civiles y Políticos promulgado en 1976, y publicado trece años después, sólo en abril de 1989, o, como con el Pacto Internacional de Derechos Económicos y Sociales, ratificado en 1976 y promulgado y publicado el 27 de mayo de 1989.

Ahora bien, desde dicha reforma, tendremos de todas maneras incluir en el bloque de constitucionalidad a ciertos tratados internacionales sobre derechos humanos. Ello, como muy bien explicaba el profesor Humberto Nogueira Alcalá, con la modificación que se hizo al texto constitucional del artículo 5 en el año $1989^{9}$, que reza lo que sigue:

El ejercicio de la soberanía reconoce como limitación el respeto a los derechos esenciales que emanan de la naturaleza humana. Es deber de los órganos del Estado respetar y promover tales derechos, garantizados por esta Constitución, así como por los tratados internacionales ratificados por Chile y que se encuentren vigentes.

De ello podemos afirmar que el límite de la soberanía son los derechos esenciales que emanan de la naturaleza humana, es decir, de los derechos humanos. Según Nogueira Alcalá, estos derechos serían:

a) los que la Carta Fundamental explicita sin taxatividad en el artículo 19¹0;

b) los que asegura el derecho internacional a través de los principios de ius cogens; los que asegura el derecho convencional internacional de derechos humanos y derecho humanitario y los que asegura el derecho internacional consuetudinario.

c) Los derechos esenciales implícitos que puedan desarrollarse en el futuro, respecto de los cuales no hay reconocimiento aún a través de las diversas fuentes del derecho interno o internacional ${ }^{11}$ ".

Además, no sólo son obligatorios los tratados sobre derechos humanos por las normas constitucionales chilenas, también lo son por asuntos de observancia internacional. En efecto, Gozaíni al analizar la obligatoriedad de determinados tratados internacionales que afectan a los países latinoamericanos y europeos, nos recuerda a la Convención de Viena sobre Derechos de los Tratados ${ }^{12}$. En efecto, el artículo 26 consagra al respecto que "Pacta sunt servanda". Todo tratado en vigor obliga a las partes y debe ser cumplido por ellas de buena fe. Es decir, lo pactado obliga, pero además debe ser cumplido, de forma efectiva para que lo suscrito y ratificado no sea una mera ilusión. Y, además el artículo 27 que expresa que, "El derecho interno y la observancia de los tratados. Una parte no podrá invocar las disposiciones de su derecho interno como justificación del incumplimiento de un tratado. Esta norma se entenderá sin perjuicio de lo dispuesto en el artículo $46^{\prime 13}$. Mayor fuerza aún, ni siquiera con

\footnotetext{
CUMPLIDO CERECEDA, Francisco. La reforma constitucional de 1989 al inciso $2^{\circ}$ del artículo $5^{\circ}$ de la Constitución: sentido y alcance de la reforma. Doctrina y Jurisprudencia. Ius et Praxis, Talca, Chile, v. 9. N. 1. p. 365-374. 2003.

8 CUMPLIDO CERECEDA, Francisco. La reforma constitucional de 1989 al inciso $2^{\circ}$ del artículo $5^{\circ}$ de la Constitución: sentido y alcance de la reforma. Doctrina y Jurisprudencia. Ius et Praxis, Talca, Chile, v. 9. n 1. pp. 365-374. 2003.

9 Constitución Política de Chile de 1980.

10 Para el lector no familiarizado con la Constitución chilena, vale informar que en el artículo 19 se encuentra una serie de garantías constitucionales, incluidas en 26 numerales, en que se desarrollan las libertades y derechos fundamentales tales como, la vida, la igualdad ante la ley, la privacidad, protección de datos personales, derecho a vivir en un medio ambiente libre de contaminación, derecho de propiedad, protección del trabajo, seguridad social, derecho a la salud, derecho a la educación, libertad de enseñanza, libertad de conciencia, entre otros.

11 NOGUEIRA ALCALÁ, Humberto. Los derechos esenciales o humanos contenidos en los tratados internacionales y su ubicación en el ordenamiento jurídico nacional: doctrina y jurisprudencia. Ius et Praxis, Talca, Chile, v. 9. n. 1. p. 403-466. 2003.

12 GOZAÍNI, Osvaldo. Derecho Procesal Transnacional: Los procedimientos en la Comisión y ante la Corte Interamericana de Derechos Humanos. México: Tirant lo Blanch, 2014.

13 NACIONES UNIDAS. Convención de Viena sobre el Derecho de los Tratados, Resolución A/CONF.39/27, de 23 de mayo de 1969. Disponible en: https://treaties.un.org/doc/Treaties/1980/01/19800127\%2000-52\%20AM/Ch_XXIII_01.pdf. Disponible
} 
derecho interno se puede obstaculizar la aplicación de un tratado internacional. Este último tratado, es decir, la Convención de Viena, ha entrado en vigor internacional en enero de $1980^{14}$. Y, Chile lo ha ratificado en el año $1981^{15}$. Por lo que desde ese punto de vista los tratados que haya ratificado le son aplicables.

A mayor abundamiento Chile ha mostrado un real interés en estar al día en materia de derechos esenciales, lo que se ha cristalizado en la suscripción y ratificación de tratados sobre derechos humanos. Así, Díaz Tolosa nos recuerda que:

La tradición en Chile ha sido respetar las normas del Derecho internacional; además forma parte de los sistemas universal y regional de protección de los derechos humanos y uno de los pilares fundamentales de su sistema político democrático es la protección a la dignidad humana ${ }^{16}$.

Así, ya es posible afirma que:

1. Los principales tratados sobre derechos humanos de la ONU son parte del bloque de constitucionalidad por contener normas de IUS COGENS.

2. En caso de no seguir doctrinas ius naturalistas o ser más formalistas exigiendo una norma o acuerdo internacional, los principales tratados sobre derechos humanos de la ONU son parte del bloque de constitucionalidad, siempre y cuando estén ratificados por Chile y estos se encuentren vigentes, aplicando el Tratado de Viena (en concreto el pacta sunt servanda y el principio de buena fe de los tratados).

3. En caso de no seguir doctrinas ius naturalista, y si se le quiere dar mayor fuerza obligatoria a la soberanía nacional (normas constitucionales) que a los acuerdos entre partes internacionales, los principales tratados sobre derechos humanos de la ONU son parte del bloque de constitucionalidad, siempre y cuando estén ratificados por Chile y estos se encuentren vigentes, aplicando el artículo 5 inciso segundo de la Constitución chilena.

Con estás dos últimas premisas, nos lleva a investigar si Chile ha suscrito, ratificado y si los tratados referidos tienen vigencia para así considerarlos como parte de su bloque de constitucionalidad.

En primer lugar, encontramos a la Convención Internacional sobre la Eliminación de todas las Formas de Discriminación Racial. Se creó por la Resolución 2106 A (XX) de la ONU, de 21 de diciembre de $1965^{17}$, teniendo vigencia internacional desde el 4 de enero de $1969^{18}$. Y, Chile en el año 1971 ha ratificado el tratado, disponiendo el Decreto Supremo 747, como sigue ${ }^{19:}$

POR CUANTO el Gobierno de la República de Chile suscribió la "Convención Internacional sobre la Eliminación de todas las Formas de Discriminación Racial”, del año 1965.

en: 22 abr. 2019.

14 NACIONES UNIDAS. Status of Treaties. Chapter XXIII. Law of Treaties. 1. Vienna Convention on the Law of Treaties. Disponible en: https://treaties.un.org/doc/Publication/MTDSG/Volume\%20II/Chapter\%20XXIII/XXIII-1.en.pdf. Disponible en: 22 abr. 2019.

15 CHILE. Ministerio de Relaciones Exteriores. Decreto Supremo 381. Promulga la convencion sobre el derecho de los tratados y su anexo, suscrita por el gobierno de chile en viena, el 23 de mayo de 1969. Publicado el 22 de junio de 1981.

16 DÍAZ TOLOSA, Regina Ingrid. Aplicación judicial en Chile del “ius cogens” como manifestación de la internacionalización del Derecho interno en materia de protección de la dignidad humana. Revista de Derecho de la Pontificia Universidad Católica de Valparaiso, Valparaíso, Chile, n. 40. p. 393-417.

17 NACIONES UNIDAS. Convención Internacional sobre la Eliminación de todas las Formas de Discriminación Racial. Resolución 2106 A $(\mathrm{XX})$, de 21 de diciembre de 1965. Disponible en: https://treaties.un.org/doc/source/docs/A_RES_2106-Eng.pdf. Disponible en: 22 abr. 2019.

18 NACIONES UNIDAS. Status of Treaties. Chapter IV. Human Rights. 2. International Convention on the Elimination of All Forms of Racial Discrimination. Disponible en: https://treaties.un.org/doc/Publication/MTDSG/Volume\%20I/Chapter\%20 IV/IV-2.en.pdf. Disponible em: 22 abr. 2019.

19 CHILE. Ministerio de Relaciones Exteriores. Decreto Supremo 747. Aprueba convención internacional sobre "eliminación de todas las formas de discriminación racial. Publicado el 12 de noviembre de 1971. 
Y POR CUANTO dicha Convención ha sido ratificada por mí, previa aprobación del Honorable Congreso Nacional, según consta en el oficio número 10.907, de 15 de Julio de 1971, del Honorable Senado y cuya copia fotostática y autenticada por el Subsecretario de Relaciones Exteriores se acompaña, dándose así cumplimiento a los trámites legales.

POR TANTO, y en uso de la facultad que me confiere el No 16 del Art. 72 de la Constitución Política del Estado, dispongo y mando que se cumpla y lleve a efecto en todas sus partes como Ley de la República publicándose copia autorizada de su texto en el Diario Oficial”.

En segundo lugar, encontramos al Pacto Internacional de Derechos Civiles y Políticos. Se creó por la Resolución 2200 A (XXI) de la ONU, de 16 de diciembre de $1966^{20}$, teniendo vigencia internacional desde el 23 de marzo de $1976^{21}$. Y, Chile ha ratificado el tratado en el año 1972, disponiendo el Decreto Supremo 778 , como sigue ${ }^{22}$ :

POR CUANTO con fecha 16 de diciembre de 1966 la Asamblea General de las Naciones Unidas por Resolución N.o 2200, adoptada en su Vigésimo Primer Período de Sesiones aprobó el Pacto Internacional de Derechos Civiles y Políticos, suscrito por Chile en esa misma fecha, cuyo texto íntegro y exacto se acompaña,

Y POR CUANTO dicho Pacto ha sido aceptado por mí, previo cumplimiento de los trámites que establece la Ley, y que el Instrumento de Ratificación ha sido depositado en la Secretaría General de las Naciones Unidas, en Nueva York, con fecha 10 de febrero de 1972,

POR TANTO, y en uso de la facultad que me confiere el artículo $5^{\circ}$ del Decreto Ley N.o 247, de 17 de enero de 1974, dispongo y mando que se cumpla y lleve a efecto en todas sus partes como Ley de la República, publicándose copia autorizada de su texto en el Diario Oficial”.

En tercer lugar, encontramos al Pacto Internacional de Derechos Económicos, Sociales y Culturales. Se creó por la Resolución 2200 A (XXI) de la ONU, de 16 de diciembre de $1966^{23}$, teniendo vigencia internacional desde el 3 de enero de $1976^{24}$. Y, Chile ha ratificado el tratado en el año 1972, disponiendo el Decreto Supremo 326, como sigue ${ }^{25}$ :

POR TANTO, con fecha 16 de septiembre de 1969 el Gobierno de Chile suscribió el Pacto Internacional de Derechos Económicos, Sociales y Culturales, adoptado por la Asamblea General de la Organización de las Naciones Unidas el 19 de diciembre de 1966.

Y POR CUANTO, dicho Pacto ha sido aceptado por mí, previa aprobación legislativa, y el Instrumento de Ratificación fue depositado en la Secretaria General de las Naciones Unidas con fecha 10 de febrero de 1972.

POR TANTO, en uso de la facultad que me confiere el artículo $32 \mathrm{~N}^{\circ} 17$ de la Constitución Política de la República, dispongo y mando que se cumpla y lleve a efecto como Ley dicho Pacto Internacional y que se publique copia autorizada de su texto en el Diario Oficial.

20 NACIONES UNIDAS. Pacto Internacional de Derechos Civiles y Políticos, Resolución 2200 A (XXI), de 16 de diciembre de 1966. Disponible en https://treaties.un.org/doc/Treaties/1976/03/19760323\%2006-17\%20AM/Ch_IV_04.pdf.

21 NACIONES UNIDAS. Status of Treaties. Chapter IV. Human Rights. 4. International Covenant on Civil and Political Rights. Disponible en: https://treaties.un.org/doc/Publication/MTDSG/Volume\%20I/Chapter\%20IV/IV-4.en.pdf. Disponible em: 22 abr. 2019.

22 CHILE. Ministerio de Relaciones Exteriores. Decreto Supremo 778. Promulga el pacto internacional de derechos civiles y politicos adoptado por la asamblea general de la organizacion de las naciones unidas por resolucion n ${ }^{\circ} 2.200$, el 16 de diciembre de $1966 \mathrm{y}$ suscrito por chile en esa misma fecha. Publicado el 29 de abril de 1989.

23 NACIONES UNIDAS. Pacto Internacional de Derechos Económicos, Sociales y Culturales, Resolución 2200 A (XXI), de 16 de diciembre de 1966. Disponible en: https://treaties.un.org/doc/Treaties/1976/01/19760103\%2009-57\%20PM/Ch_IV_03.pdf. Disponible en: 22 abr. 2019.

24 NACIONES UNIDAS. Status of Treaties. Chapter IV. Human Rights. 3. International Covenant on Economic, Social and Cultural Rights. Disponible en: https://treaties.un.org/doc/Publication/MTDSG/Volume\%20I/Chapter\%20IV/IV-3.en.pdf. Disponible em: 22 abr. 2019.

25 CHILE. Ministerio de Relaciones Exteriores. Decreto Supremo 326. Promulga el pacto internacional de derechos economicos, sociales y culturales, adoptado por la asamblea general de la organizacion de las naciones unidas el 19 de diciembre de 1966, suscrito por chile el 16 de septiembre de 1969. Publicado el 27 de mayo de 1989. 
En cuarto lugar, encontramos a la Convención sobre la eliminación de todas las formas de discriminación contra la mujer. Se creó por la Resolución 34/180, de 18 de diciembre de 1979²6, teniendo vigencia internacional desde el 3 de septiembre de $1981^{27}$. Y, Chile ha ratificado el tratado en el año 1989, disponiendo el Decreto Supremo 789, como sigue ${ }^{28}$ :

POR CUANTO, con fecha 17 de julio de 1980 el Gobierno de Chile suscribió la Convención sobre la Eliminación de todas las Formas de Discriminación contra la Mujer, adoptada por la Asamblea General de las Naciones Unidas el 18 de diciembre de 1979.

POR CUANTO, dicha Convención ha sido aceptada por mí, previa aprobación de la Honorable Junta de Gobierno, según consta en el Acuerdo adoptado con fecha 17 de octubre de 1989.

POR TANTO, en uso de la facultad que me confieren los artículos $32 \mathrm{~N}^{\circ} 17$ y 50 número 1) de la Constitución Política de la República, dispongo y mando que se cumpla y lleve a efecto como Ley y que se publique copia autorizada de su texto en el Diario Oficial.

En quinto lugar, encontramos a la Convención contra la Tortura y Otros Tratos o Penas Crueles, Inhumanos o Degradantes. Se creó por la Resolución 39/46 de la ONU, de 10 de diciembre de 1984²9, teniendo vigencia internacional desde el 26 de junio de $1987^{30}$. Y, Chile ha ratificado tratado en el año 1988, disponiendo el Decreto Supremo 808, como sigue ${ }^{31}$ :

POR CUANTO, con fecha 23 de septiembre de 1987, se suscribió la Convención contra la Tortura y otros Tratos o penas Crueles, Inhumanas o Degradantes, adoptada por la Asamblea General de la Organización de las Naciones Unidas mediante la resolución 39/46, de fecha 10 de diciembre de 1984.

Y POR CUANTO, dicha Convención ha sido aceptada por mí, previa aprobación de la Honorable Junta de Gobierno, según consta del Acuerdo adoptado con fecha 13 de septiembre de 1988; y el Instrumento de Ratificación se depositó ante el Secretario General de la Organización de las Naciones Unidas con fecha 30 de septiembre de 1988 con las siguientes reservas:

a) $\mathrm{Al}$ artículo 2 párrafo tercero, en cuanto modifica el principio de la "obediencia reflexiva" consagrado en la legislación interna chilena, en el sentido de que el Gobierno de Chile aplicará lo dispuesto en dicha norma internacional al personal sujeto al Código de Justicia Militar, respecto a los subalternos, siempre que la orden, notoriamente tendiente a la perpetración de los actos indicados en el artículo $1^{\circ}$, no sea insistida por el superior ante la representación del subalterno.

b) $\mathrm{Al}$ artículo 3 en razón del carácter discrecional y subjetivo en que está redactada la norma.

c) El Gobierno de Chile declara que en sus relaciones con los Países Americanos que sean partes de la Convención Internacional para Prevenir y Sancionar la Tortura, aplicará dicha Convención en los casos en que existan incompatibilidades entre sus disposiciones y las de la presente Convención.

d) De conformidad con lo establecido en el artículo 28 párrafo $1^{\circ}$, el Gobierno de Chile no reconoce la competencia del Comité contra la Tortura según se establece en el artículo 20 de la presente Convención.

26 NACIONES UNIDAS. Convención sobre la eliminación de todas las formas de discriminación contra la mujer, Resolución 34/180, de 18 de diciembre de 1979. Disponible en: https://treaties.un.org/doc/Treaties/1981/09/19810903\%2005-18\%20AM/ Ch_IV_8p.pdf. Acceso en: 22 abr. 2019.

27 NACIONES UNIDAS. Status of Treaties. Chapter IV. Human Rights. 8. Convention on the Elimination of All Forms of Discrimination against Women. Disponible en: https://treaties.un.org/doc/Publication/MTDSG/Volume\%20I/Chapter\%20IV/ IV-8.en.pdf. Acceso en: 22 abr. 2019.

28 CHILE. Ministerio das Relaciones Exteriores. Decreto Supremo 789. Promulga la convencion sobre la eliminacion de todas las formas de discriminacion contra la mujer, adoptada por la asamblea general de las naciones unidas el 18 de diciembre de 1979. Publicado el 09 de diciembre de 1989.

29 CHILE. Ministerio de Relaciones Exteriores. Decreto Supremo 808. Promulga la convencion contra la tortura y otros tratos o penas crueles, inhumanos o degradantes, adoptada por la asamblea general de la organizacion de las naciones unidas mediante resolucion 39/46, de fecha 10 de diciembre de 1984. Publicado el 26 de noviembre de 1988.

30 NACIONES UNIDAS. Convención contra la Torturay Otros Tratos o Penas Crueles, Inbumanos o Degradantes, Resolución 39/46, de 10 de diciembre de 1984. Disponible en: https:/ /treaties.un.org/doc/Treaties/1987/06/19870626\%2002-38\%20AM/Ch_IV_9p.pdf. Acceso en: 22 abr. 2019.

31 NACIONES UNIDAS. Status of Treaties. Chapter IV. Human Rights. 9. Convention against Torture and Other Cruel, Inbuman or Degrading Treatment or Punishment. Disponible en: https://treaties.un.org/doc/Publication/MTDSG/Volume\%20I/Chapter\%20IV/ IV-9.en.pdf Acceso en:22 abr. 2019. 
e) El Gobierno de Chile no se considerará obligado por lo dispuesto en el artículo 30 párrafo $1^{\circ}$ de la Convención.

POR TANTO, en uso de la facultad que me confieren los artículos $32 \mathrm{~N}^{\circ} 17$ y 50 número 1) de la Constitución Política de la República, dispongo y mando que se cumpla esta Convención en todas sus partes, y que se publique copia autorizada de su texto en el Diario Oficial.

Además, respecto de dicho tratado hay que considerar a los Decretos Supremos, 39 de $1991^{32}$ y el 1562 de $1999^{33}$, que realizan retiro de reservas que habían sido formuladas por Chile en su documento de ratificación.

En sexto lugar, encontramos a la Convención sobre los Derechos del Niño. Se creó por la Resolución 44/25 de la ONU, de 20 de noviembre de $1989^{34}$, teniendo vigencia internacional desde el 2 de septiembre de $1990^{35}$. Y, Chile ha ratificado el tratado en el año 1990, disponiendo el Decreto Supremo 830, como sigue $^{36}$ :

POR CUANTO, con fecha 26 de enero de 1990 el Gobierno de Chile suscribió la Convención sobre los Derechos del Niño, adoptada por la Asamblea General de la Organización de las Naciones Unidas el 20 de Noviembre de 1989.

Y POR CUANTO, dicha Convención ha sido aceptada por mí, previa aprobación del Congreso Nacional, según consta en el oficio $\mathrm{N}^{\circ} 379$ del Honorable Senado, de fecha 10 de julio de 1990; y el Instrumento de Ratificación se depositó ante el Secretario General de la Organización de las Naciones Unidas con fecha 13 de agosto de 1990.

POR TANTO, en uso de la facultad que me confieren los artículos $32 \mathrm{~N}^{\circ} 17$ y $50 \mathrm{~N}^{\circ}$ 1) de la Constitución Política de la República, dispongo y mando que se cumpla y lleve a efecto como Ley y que se publique copia autorizada de su texto en el Diario Oficial.

Y, demás hay que considerar la ratificación de la enmienda al párrafo 2 del artículo 43 de la Convención sobre derechos del niño, lo que consta en el Decreto Supremo 29 de $2004^{37}$.

En séptimo lugar, encontramos a la Convención internacional sobre la protección de los derechos de todos los trabajadores migratorios y de sus familiares. Se creó por la Resolución 45/158 de la ONU, de 18 de diciembre de $1990^{38}$, teniendo vigencia internacional desde el año $2003^{39}$. Y, Chile ha ratificado el tratado en el año 2005, disponiendo el Decreto Supremo 84, como sigue ${ }^{40}$ :

Que con fecha 18 de diciembre de 1990, la Asamblea General de las Naciones Unidas adoptó la Convención internacional sobre la protección de los derechos de todos los trabajadores migratorios y

32 CHILE. Ministerio de Relaciones Exteriores. Decreto Supremo 39. Retira las reservas formuladas a la convencion contra la tortura y otros tratos o penas cruele, inhumanos o degradantes, adoptada por la asamblea general de la organizacion de las naciones unidas el 10 de diciembre de 1984. Publicado el 13 de marzo de 1991.

33 CHILE. Ministerio de Relaciones Exteriores. Decreto Supremo 1562. Retira la reserva formulada al articulo 30, parrafo 1, de la convencion contra la tortura y otros tratos o penas crueles, inhumanos o degradantes. Publicado el 23 de diciembre de 1999.

34 NACIONES UNIDAS. Resolución 44/25, de 20 de noviembre de 1989. Convención sobre los Derechos del Niño. Disponible en: https://treaties.un.org/doc/Treaties/1990/09/19900902\%2003-14\%20AM/Ch_IV_11p.pdf. Acceso en: 22 abr. 2019.

35 NACIONES UNIDAS. Status of Treaties. Chapter IV. Human Rights. 11. Convention on the Rights of the Child. Disponible en: https://treaties.un.org/doc/Publication/MTDSG/Volume\%20I/Chapter\%20IV/IV-11.en.pdf Acceso en: 22 abr. 2019

36 CHILE. Ministerio de Relaciones Exteriores. Decreto Supremo 830. Promulga convencion sobre los derechos del niño. Publicado el 27 de septiembre de 1990.

37 CHILE. Ministerio de Relaciones Exteriores. Decreto Supremo 29. Promulga la enmienda al parrafo 2 del articulo 43 de la convencion sobre los derechos del niño. Publicado el 30 de abril de 2004.

38 NACIONES UNIDAS. Resolución 45/158, de 18 de diciembre de 1990. Convención internacional sobre la protección de los derechos de todos los trabajadores migratorios y de sus familiares. Disponible en: https://treaties.un.org/doc/Treaties/1990/12/19901218\%20 08-12\%20AM/Ch_IV_13p.pdf. Acceso en: 22 abr. 2019.

39 NACIONES UNIDAS. Status of Treaties. Chapter IV. Human Rights. 13. International Convention on the Protection of the Rights of All Migrant Workers and Members of their Families. Disponible en: https://treaties.un.org/doc/Publication/MTDSG/Volume\%20I/ Chapter\%20IV/IV-13.en.pdf. Acceso en: 22 abr. 2019.

40 CHILE. Ministerio de Relaciones Exteriores. Decreto Supremo 84. Promulga la convencion internacional sobre la proteccion de los derechos de todos los trabajadores migratorios y de sus familiares. Publicado el 08 de junio de 2005. 
de sus familiares, suscrita por Chile el 24 de septiembre de 1993.

Que dicha Convención fue aprobada por el Congreso Nacional, según consta en el oficio $\mathrm{N}^{\circ}$ 4.746, de 8 de enero de 2004, de la Honorable Cámara de Diputados.

Que el instrumento de ratificación se depositó ante el Secretario General de la Organización de las Naciones Unidas con fecha 21 de marzo de 2005, con las siguientes reservas

"La República de Chile formula reserva a lo preceptuado en el número 5 del artículo 22, el que considera inaplicable a su respecto".

"La República de Chile dará por cumplido lo dispuesto en el número 2 del artículo 48 mediante los acuerdos internacionales para evitar la doble imposición, celebrados o que se celebren en el futuro". Que, en consecuencia, la mencionada Convención entrará en vigor para Chile el 1 de julio de 2005.

En octavo lugar, encontramos a la Convención sobre los derechos de las personas con discapacidad. Se creó por la Resolución A/RES/61/106 de la ONU, 13 de diciembre de $2006^{41}$, teniendo vigencia internacional desde el 3 de mayo de $2008^{42}$. Y, Chile ha ratificado el tratado en el año 2008, disponiendo el Decreto Supremo 201, como sigue ${ }^{43}$ :

Que, con fecha 13 de diciembre de 2006, la Asamblea General de la Organización de las Naciones Unidas adoptó, en su $61^{\circ}$ Período Ordinario de Sesiones, en Nueva York, la Convención sobre los Derechos de las Personas con Discapacidad y su Protocolo Facultativo.

Que dicha Convención y su Protocolo Facultativo fueron aprobados por el Congreso Nacional, según consta en el Oficio $\mathrm{N}^{\mathrm{o}} 7.543$, de 2 de julio de 2008, de la Honorable Cámara de Diputados.

Que, con fecha 29 de julio de 2008, se depositó ante el Secretario General de las Naciones Unidas el Instrumento de Ratificación de la Convención y su Protocolo Facultativo y, en consecuencia, ambos instrumentos internacionales entrarán en vigor para Chile el 28 de agosto de 2008.

En noveno lugar, encontramos a la Convención internacional para la protección de todas las personas contra las desapariciones forzadas. Se creó por la Resolución A/RES/61/177 de la ONU, de 20 de diciembre de $2006^{44}$, teniendo vigencia internacional desde el 23 de diciembre de $2010^{45}$. Y, Chile ha ratificado el tratado en el año 2009, disponiendo el Decreto Supremo 280, como sigue ${ }^{46}$ :

Que la Asamblea General de las Naciones Unidas adoptó el 20 de diciembre de 2006, en Nueva York, Estados Unidos de América, la Convención Internacional para la Protección de Todas las Personas Contra las Desapariciones Forzadas.

Que dicha Convención fue aprobada por el Congreso Nacional, según consta en el oficio No 8.351, de 6 de octubre de 2009, de la Honorable Cámara de Diputados.

Que el Tribunal Constitucional, por sentencia Rol No 1483-2009, de fecha 29 de septiembre de 2009, declaró que no le corresponde a ese Tribunal pronunciarse sobre la mencionada Convención, por no

41 NACIONES UNIDAS. Convención sobre los derechos de las personas con discapacidad, Resolución A/RES/61/106, de 13 de diciembre de 2006. Disponible en: https://treaties.un.org/doc/Publication/CTC/Ch_IV_15.pdf [Fecha de consulta 22 de abril de 2019].

42 NACIONES UNIDAS. Status of Treaties. Chapter IV. Human Rights. 15. Convention on the Rights of Persons with Disabilities. Disponible en: https://treaties.un.org/doc/Publication/MTDSG/Volume\%20I/Chapter\%20IV/IV-15.en.pdf [Fecha de consulta 22 de abril de 2019].

43 CHILE, Decreto Supremo 201, "PROMULGA LA CONVENCIÓN DE LAS NACIONES UNIDAS SOBRE LOS DERECHOS DE LAS PERSONAS CON DISCAPACIDAD Y SU PROTOCOLO FACULTATIVO”, Ministerio de Relaciones Exteriores, publicado el 17 de septiembre de 2008.

44 NACIONES UNIDAS. Resolución A/RES/61/177, de 20 de diciembre de 2006. Convención internacional para la protección de todas las personas contra las desapariciones forzadas. Disponible en: https://treaties.un.org/doc/Publication/CTC/Ch_IV_16.pdf [Fecha de consulta 22 de abril de 2019].

45 NACIONES UNIDAS. Status of Treaties. Chapter IV. Human Rights. 16. International Convention for the Protection of All Persons from Enforced Disappearance. Disponible en: https://treaties.un.org/doc/Publication/MTDSG/Volume\%20I/Chapter\%20IV/IV-16.en.pdf [Fecha de consulta 22 de abril de 2019].

46 CHILE. Ministerio de Relaciones Exteriores. Decreto Supremo 280. Promulga la convención internacional para la protección de todas las personas contra las desapariciones forzadas., publicado el 16 de abril de 2011. 
contemplar normas que versen sobre materias propias de Leyes Orgánicas Constitucionales.

Que con fecha 8 de diciembre de 2009 se depositó el Instrumento de Ratificación de la referida Convención ante el Secretario General de las Naciones Unidas, con las siguientes Declaraciones:

"La República de Chile declara, conforme a lo establecido en el Artículo 31 de la presente Convención, que reconoce la competencia del Comité para recibir y examinar las comunicaciones presentadas por personas que se encuentren bajo la jurisdicción del Estado de Chile, o en nombre de ellas, que aleguen ser víctimas de violaciones por éste de las disposiciones de la presente Convención".

"La República de Chile declara, conforme a lo establecido en el Artículo 32 de la presente Convención, que reconoce la competencia del Comité para recibir y examinar las comunicaciones en que un Estado Parte alegue que otro Estado Parte no cumple con las obligaciones que le impone la presente Convención".

Que, de conformidad con el Artículo 39, numeral 1, de dicha Convención, ésta entrará en vigor internacional el 23 de diciembre de 2010.

Con todo, desde el punto de vista normativo se cumple con el requisito para que los tratados referidos sean parte del bloque de constitucionalidad de Chile. Todos tratan sobre derechos humanos, es decir, pactos que reconocen, crean o desarrollan derechos esenciales de la naturaleza humana. Como tratados internacionales ratificados se deben aplicar por el pacta sunt servanda y/o sumado a ello, por aplicación el artículo 5 inciso segundo de la Constitución chilena, pues han sido ratificados por Chile y se encuentran vigentes.

Ahora bien, ¿Esto será así también en los tribunales de justicia? Es lo que responderá el siguiente punto a tratar.

\section{De la teoría a la práctica: inclusión de los principales tratados sobre derechos humanos de la ONU en el bloque de constitucionalidad chileno. Su aplicación en los máximos tribunales}

El día 1 de marzo de 2018 se inauguraba el año judicial. El excelentísimo Ministro y Presidente de la Corte Suprema señor Haroldo Brito Cruz daba cuenta de la gestión del Poder Judicial exponiendo de cómo se ha cumplido el mandato y por otro lado, señalaba lo que debería hacerse para mejorar la administración de justicia. En efecto, hubo una serie de reflexiones y estadísticas relevantes para todo estudiante, litigante o académico que se dedique al Derecho. Una muy significativa, el gran número de porcentaje de causas que conoce el máximo tribunal tratan sobre derechos humanos, ya sea provenientes del recurso de amparo, del recurso de protección, del recurso de nulidad en materia penal o por medios de impugnación originados en tutelas de derechos fundamentales en el trabajo. En concreto, expresaba lo siguiente ${ }^{47}$ :

Dejando a un lado las apelaciones de los recursos de protección contra Isapres, que siguen su tendencia histórica y representan un importante número de casos -más del 70\% del total-, cabe también preguntarse qué asuntos conoce este tribunal. La respuesta es significativa: desarrollamos un rol orientado a la aplicación directa de la Constitución, ya que más de un tercio de lo que conocemos tiene como origen una acción constitucional, tales como el recurso de amparo (20\%) o de protección (16\%), sin considerar los recursos en lo penal que se fundamentan en normas de esta clase, ni las acciones de tutela de derechos fundamentales en lo laboral.

Aquello significa que la administración de justicia necesita estar al día en materia de derechos humanos. Es así como no sólo magistrados y funcionarios del poder judicial deben considerar normas protectoras de derechos fundamentales, sino que también, uno de los principales auxiliares de justicia, los abogados, pueden y deben utilizarlas en sus argumentaciones para una mejor resolución del caso. El mismo Presidente de

47 BRITO CRUZ, Haroldo. Cuenta pública presidencia Corte Suprema 2018. Discurso del Presidente de la Corte Suprema señor Haroldo Brito Cruz. 2018. Disponible en http://www.diariooficial.interior.gob.cl/publicaciones/2018/04/06/42025/01/1370510. pdf. Acceso en:26 enero 2019. 
la Excelentísima Corte en su discurso inaugural de 2018 indicaba que se propone incorporar como política la perspectiva de derechos humanos en la resolución de los asuntos ${ }^{48}$.

Entonces, como política de administración de justicia se considera aplicar la normativa sobre derechos humanos en las resoluciones judiciales. En los siguientes párrafos se dan muestras de la aplicación de cada uno de los tratados internacionales referidos en el punto anterior para determinar que si son o no parte del bloque de constitucionalidad en Chile. Es decir, veremos como del texto positivo trascienden a la aplicación práctica en tribunales de justicia.

En primer lugar, revisemos un caso sobre la aplicación de la Convención Internacional sobre la Eliminación de todas las Formas de Discriminación Racial. En efecto. La Cámara de Diputados remitió copia autenticada del proyecto de ley aprobado por el Congreso Nacional, que establece medidas contra la discriminación (Boletín N $\left.{ }^{\circ} 3815-07\right)^{49}$, con el objeto de que el Tribunal Constitucional, en conformidad a lo dispuesto en el artículo 93, inciso primero, $\mathrm{N}^{\circ} 1^{\circ}$, de la Constitución Política de la República, ejerza el control de constitucionalidad respecto del inciso segundo de su artículo $1^{\circ}$ y de sus artículos $3^{\circ}, 6^{\circ}$ y $13^{50}$.

El tribunal resolvió respecto de las disposiciones de las letras b), c), d) y e) del artículo $6^{\circ}$ y en el artículo 13 del proyecto de ley sometido a control, que no se pronunciaría respecto del examen preventivo de constitucionalidad, debido a que dichos preceptos no son propios de ley orgánica constitucional. Y, respecto de las disposiciones contenidas en el inciso segundo del artículo $1^{\circ}$, en el artículo $3^{\circ}$ y en la letra a) y el inciso final del artículo $6^{\circ}$, del proyecto de ley remitido a control, resolvió que no son contrarias a la Carta Fundamental. Para resolver, tuvo presente en sus considerandos a la Convención Internacional sobre la Eliminación de todas las Formas de Discriminación Racial (Considerando decimoséptimo) ${ }^{51}$.

En cuanto a un voto particular, que es relevante en la aplicación de tratados internacionales en Chile, es menester tener presente lo prevenido por la Ministra señora Marisol Peña Torres, que agrega además la tesis de extender el control preventivo obligatorio de constitucionalidad al inciso primero del artículo $2^{\circ}$ del proyecto de ley examinado. En efecto, en dicho voto particular, se aporta en el sentido de dar contenido a la interpretación del concepto de "discriminación arbitraria", especialmente en un asunto donde no hay un consenso conceptual y tampoco hay una definición explicita de discriminación. Para ello, se considera para considera en la creación de un concepto jurisprudencial de discriminación, entre otros tratados, a la Convención Internacional sobre la Eliminación de todas las Formas de Discriminación Racial (Voto particular, III, Ministra señora Marisol Peña Torres) ${ }^{52}$.

En segundo lugar, revisemos un caso sobre la aplicación del Pacto Internacional de Derechos Civiles y Políticos. El Décimo Noveno Juzgado Civil de Santiago, en juicio ejecutivo de cobro de obligaciones tributarias del Título V del Libro III del Código Tributario, acogió una excepción de prescripción de la acción de cobro del Fisco opuesta por un contribuyente, ordenándose el alzamiento de la ejecución respecto un impuesto ${ }^{53}$. Impugnada esa decisión, la Ilustrísima Corte de Apelaciones de Santiago la revocó, declarando en su lugar que se rechaza la indicada excepción debiendo seguir adelante la ejecución. ${ }^{54}$ Posteriormente se dedujeron recursos de casación en la forma y el fondo, los que fueron rechazados, pero con un voto en contra o particular ${ }^{55}$.

\footnotetext{
48 BRITO CRUZ, Haroldo. Cuenta pública presidencia Corte Suprema 2018. Discurso del Presidente de la Corte Suprema señor Haroldo Brito Cruz. 2018. Disponible en: http://www.diariooficial.interior.gob.cl/publicaciones/2018/04/06/42025/01/1370510. pdf Acceso en:26 enero 2019.

49 Hoy es una ley publicada: CHILE. Ley No 20.609, de 24 de julio de 2012. Establece medidas contra la discriminación. Disponible en: https://www.leychile.cl/Navegar?idNorma=1042092. Acceso em: 22 abr. 2019. (Conocida comúnmente como "Ley Zamudio").

50 CHILE. Excelentísimo Tribunal Constitucional. Rol No 2.231-2012.

51 CHILE. Excelentísimo Tribunal Constitucional. Rol No 2.231-2012. Sentencia de 01 abril de 2013.

52 CHILE. Excelentísimo Tribunal Constitucional. Rol No 2.231-2012. Sentencia de 01 abril de 2013.

53 CHILE. Décimo Noveno Juzgado Civil de Santiago. Rol No C-24.868-2009. Sentencia de 16 de enero de 2014.

54 CHILE. Ilustrísima Corte de Apelaciones de Santiago. Rol No 1.969-2014. Civil, Sentencia de 26 de diciembre de 2014. Rol No 1.9692014. Civil, Sentencia de 26 de diciembre de 2014.

55 CHILE. Excelentísima Corte Suprema Rol N².285-2015, Sentencia de 25 de enero de $2016 .$.
} 
Es así como la Excelentísima Corte Suprema resuelve que en los autos aparece como interrumpida la prescripción que se invoca y por ello no debe acogerse la prescripción. Fue clave en los autos el requerimiento de pago practicado el 11 de marzo de 2002 que produjo el efecto de interrumpir el plazo de prescripción de la acción de cobro, que con anterioridad y por un prolongado tiempo se había mantenido suspendido. Vale decir, desde el plazo legal en que debió efectuarse el pago, el 30 de abril de 1993, principió a correr el término de la prescripción de la acción de cobro, y habiéndose reclamado la liquidación del impuesto, se suspendió dicho plazo, por lo que una vez dictada la sentencia y ordenado el giro, el 21 de septiembre de 2001, comenzó a correr desde esa fecha el plazo de prescripción que se vio interrumpido por haberse practicado requerimiento de pago, el 11 de marzo de 2002, como se dijo ${ }^{56}$.

No obstante, el voto en contra considera acoger el recurso de casación en el fondo y declarar en la sentencia de reemplazo en favor del contribuyente pues el respeto a las normas constitucionales y de derecho internacional exigen que la acción de la justicia sea rápida y oportuna, tanto en escuchar a los justiciables, como en resolver los problemas planteados, sean ellos del ámbito civil o del penal, debiendo resolverse el conflicto en un plazo razonable, esto es, ajustado a la razón. En tal perspectiva, no puede aceptarse, que el cobro se extienda por más de una década -en este caso veintidós años-, plazo considerado desde la data de exigibilidad de los impuestos hasta la fecha de expedición de esta sentencia ${ }^{57}$.

En tercer lugar, revisemos un caso sobre la aplicación del Pacto Internacional de Derechos Económicos, Sociales y Culturales. Se recurre de protección en favor de una menor de edad en contra de un determinado Colegio, ya que éste habría negado la renovación de matrícula (estudiante de séptimo a octavo básico). La Ilustrísima Corte de Apelaciones de Santiago rechaza el recurso, estimando que el contrato que se había suscrito era de carácter anual, para luego dejar en absoluta libertad a las partes para renovarlo o no. Esta libertad, naturalmente, importa la suscripción un nuevo acuerdo de voluntades y de un nuevo contrato, para los efectos de obtener la matrícula para el año lectivo 2013. Ello, llevó al actor a interponer recurso de apelación respecto del fallo ${ }^{58}$.

Se revoca la sentencia de primera instancia en favor del recurrente. La Excelentísima Corte Suprema estima que es abiertamente contrario a derecho, por las razones surgidas de los conceptos normativos esbozados en la sentencia. En efecto, resulta del todo incompatible con la idea de unidad y progresividad de todo proceso educativo, dejarlo entregado a la mera voluntad de cualquiera de las partes, en cuanto a la promoción a nivel sucedáneo, premisa ésta que en todo caso es valedera para los cursos de un mismo ciclo, en la especie, la promoción del séptimo al octavo año del ciclo básico (Considerando sexto al noveno ${ }^{59}$.

En cuarto lugar, revisemos un caso sobre la aplicación de la Convención sobre la eliminación de todas las formas de discriminación contra la mujer. Una determinada institución educacional con sede en Chillán presenta demanda de desafuero en contra de una de sus trabajadoras embarazadas con contrato a plazo fijo, a fin de que se autorice para poner término al contrato de laboral suscrito por ambas partes. La acción deducida es rechazada ${ }^{60}$, al igual que el recurso de nulidad deducido para conocimiento de la Ilustrísima Corte de Apelaciones de Chillán ${ }^{61}$, como también la presentación del recurso de unificación de jurisprudencia resuelto por la Excelentísima Corte Suprema ${ }^{62}$.

El máximo tribunal, teniendo a la vista las sentencias contradictorias, una, que por un lado darían lugar al desafuero y otra que no (la de autos), resuelve rechazar el recurso de unificación de jurisprudencia en favor de la trabajadora, considerando para resolver que se debe tener presente en la controversia que la maternidad

\footnotetext{
CHILE. Excelentísima Corte Suprema Rol N².285-2015, Sentencia de 25 de enero de 2016.

CHILE. Excelentísima Corte Suprema. Rol No 2.285-2015, Sentencia de 25 de enero de 2016.

CHILE. Ilustrísima Corte de Apelaciones de Santiago. Rol No 41.989-2012, Protección, Sentencia de 01 abril de 2013.

CHILE, Excelentísima Corte Suprema, Rol No 3.015-2013, Sentencia de 05 de agosto de 2013.

CHILE Juzgado de Letras del Trabajo de Chillán. RIT O-224-2013, Sentencia de 08 de enero de 2014.

1 CHILE. Ilustrísima Corte de Apelaciones de Chillán. Rol No 12-2014, Sentencia de 24 de marzo de 2014. Reforma Laboral.

62 CHILE. Excelentísima Corte Suprema. Rol Nº 8.891-2014, Sentencia de 15 de enero de 2015.
} 
se encuentra protegida en instrumentos internacionales, entre otros, por el Convención sobre eliminación de todas las formas de discriminación contra la mujer (Considerando octavo y undécimo) ${ }^{63}$.

En quinto lugar, revisemos un caso sobre la aplicación de la Convención contra la Tortura y Otros Tratos o Penas Crueles, Inhumanos o Degradantes. Se presenta demanda en un Juzgado Civil de Santiago para obtener resarcimiento por daño moral debido a prisión política y tortura a que fueron sometidos. En primera instancia se acoge parcialmente la demanda por lo que se condena al Fisco de Chile a indemnizar a los actores $^{64}$, mientras que en alzada se rebajan los montos a resarcir. Ambas partes presentan recursos de casación en el fondo, los demandantes para elevar las sumas de dinero a indemnizar mientras que el demandado para que se acogiera excepción de pago y prescripción ${ }^{65}$.

Se rechazan los recursos interpuestos por ambas partes por la Excelentísima Corte Suprema. A los demandantes, porque la apreciación pecuniaria del daño moral puede y debe ser asumida prudencialmente por el juez, por lo que no es susceptible de revisión por la vía de la casación en el fondo (Considerando cuarto). Y, al demandado por estimar que los agravios fueron producidos a consecuencia de delitos de lesa humanidad, lo que encuentra fundamento en paradigmas generales del Derecho Internacional de los Derechos Humanos y su consagración normativa en los tratados internacionales ratificados por Chile, los cuales obligan al Estado a reconocer y proteger este derecho a la reparación completa, en virtud de lo ordenado en los artículos 5, inciso segundo y 6 de la Constitución Política de la República (Considerando séptimo a décimo tercero) ${ }^{66}$.

En sexto lugar, revisemos un caso sobre la aplicación de la Convención sobre los Derechos del Niño. Se interponen dos recursos de protección en favor de una determinada cantidad de estudiantes de un Liceo de la comuna de Providencia, ya que no se les renovaría la matrícula para el siguiente año de estudios. Para ello, el establecimiento educacional habría aplicado medidas disciplinarias al respecto. Se acoge el recurso, que posteriormente fue confirmado por la Excelentísima Corte Suprema ${ }^{67}$.

Resuelve la Ilustrísima Corte de Apelaciones de Santiago que en favor de los estudiantes. En efecto, estima que ha resultado confuso y las medidas aplicadas desproporcionadas, revistiendo el establecimiento educacional visos de ilegalidad y arbitrariedad en su actuar. Entre otros aspectos, para resolver, tuvo presente que en su mayoría los estudiantes eran menores de dieciocho años, por lo que necesariamente debe traerse a colación a la Convención de Derechos del niño (Considerando undécimo) ${ }^{68}$.

En séptimo lugar, revisemos un caso sobre la aplicación de la Convención internacional sobre la protección de los derechos de todos los trabajadores migratorios y de sus familiares. Se presenta requerimiento de inaplicabilidad respecto de determinadas oraciones de los artículos 227 y 320 del Código Procesal Penal y del artículo 411 quáter del Código Penal por estimar que se infringen lo dispuesto en los numerales $2^{\circ}$ y $3^{\circ}$ del artículo 19 de la Carta Fundamental. La declaración de inaplicabilidad se solicita para que surta efectos en la gestión pendiente consistente en una causa que se sigue ante el Juzgado de Garantía de Pichilemu por los supuestos delitos de tráfico ilícito de migrantes y trata de personas, previstos y sancionados en los artículos 411 bis y 411 quáter del Código Penal ${ }^{69}$.

Se rechaza el requerimiento de inaplicabilidad. El excelentísimo Tribunal Constitucional resuelve que, lo que corresponde apreciar en la figura penal impugnada no es una integración analógica de la ley, sino que la ley contempla un elemento normativo ("esclavitud o prácticas análogas a ésta”), para y cuya definición y

63 CHILE. Excelentísima Corte Suprema. Rol No 8.891-2014, Sentencia de 15 de enero de 2015.

${ }^{64}$ CHILE. Vigésimo quinto Juzgado Civil de Santiago. Rol No C-31.513-2009, Sentencia de 22 de julio de 2009.

65 CHILE. Ilustrísima Corte de Apelaciones de Santiago. Rol Nº 6.891-2013, Civil, Sentencia de 10 de diciembre de 2014.

66 CHILE. Excelentísima Corte Suprema. Rol N².289-2015, Sentencia de 29 de marzo de 2016.

67 CHILE. Ilustrísima Corte de Apelaciones de Santiago. Rol No 2.678-2012, Sentencia de 26 de abril de 2012, (Acumulado Rol 3.039-2012), Protección,.

68 CHILE. Excelentísima Corte Suprema. Rol N³ 3.880-2012, Sentencia de 28 de mayo de 2012.

69 CHILE. Excelentísimo Tribunal Constitucional. Rol No 2.615-14, Sentencia de 30 de octubre de 2014. 
conceptualización concreta viene en auxilio del juez todo el corpus iuris aludido, entre otros, la Convención internacional sobre la protección de los derechos de todos los trabajadores migratorios y de sus familiares, la Convención contra la Delincuencia Organizada Transnacional y sus dos Protocolos, que constituye un corpus iuris internacional solidadmente asentado sobre la materia de esclavitud en todas sus formas (Considerando décimo, décimo segundo, décimo tercero, duodécimo octavo) ${ }^{70}$.

En octavo lugar, revisemos un caso sobre la aplicación de la Convención sobre los derechos de las personas con discapacidad. Una serie de agrupaciones y asociaciones presentan un recurso de protección en favor de las personas sordomudas del país en contra de contra de diversos canales de Televisión. En opinión de los recurrentes las emisoras televisivas no habrían hecho accesibles el recuadro de intérprete en lengua de señas chilena en diversas transmisiones de hechos y eventos de alto impacto y trascendencia social, aludiendo específicamente al Festival de la Canción de Viña del Mar, a la erupción del volcán Villarrica, a la audiencia de formalización de la investigación del denominado caso Penta y al incendio que afectó a las ciudades de Valparaíso y Viña del Mar. A su turno, los recurridos informan, en general, que cumplen con la normativa sobre programación. Se rechaza el recurso por la Ilustrísima Corte de Apelaciones de Santiago ${ }^{71}$.

Se confirma la decisión de primera instancia por la Excelentísima Corte Suprema. Ello, ya que en los autos aparece de manifiesto que los canales de televisión recurridos, al incorporar el sistema de subtitulado oculto o "closed caption" a la transmisión de los programas de televisión referidos por las asociaciones recurrentes en su libelo, han dado estricto cumplimiento a la normativa que rige la materia. Entre otras normas, se tuvo presente a la Convención de las Naciones Unidas sobre los Derechos de las Personas con Discapacidad y su Protocolo Facultativo (Considerando tercero) ${ }^{72}$.

En noveno lugar, revisemos un caso sobre la aplicación de la Convención internacional para la protección de todas las personas contra las desapariciones forzadas. En primera instancia se sentencia en el año 2012 a cinco agentes del Estado por su responsabilidad como autores del delito de secuestro calificado perpetrado en los años ochenta. En lo que corresponde a la acción civil deducida en el proceso, se condena al Fisco al pago de una determinada cantidad de dinero por concepto de daño moral. En 2014 la Ilustrísima Corte de Apelaciones de Santiago desestimó una casación en la forma interpuesta. Además, confirmó el fallo de primera instancia (en lo penal, aunque reduciendo la pena), y, en lo civil, rechazó la demanda por incompetencia absoluta para conocer de la acción indemnizatoria entablada. Contra la sentencia del tribunal de alzada se dedujeron recursos de casación en el fondo ${ }^{73}$.

Se acogen las pretensiones de los actores. En tal sentido, la Excelentísima Corte Suprema tiene por rechazadas las excepciones de incompetencia, prescripción, improcedencia e inexistencia de responsabilidad opuestas por el Fisco de Chile. Y, se confirma la sentencia impugnada condenando al Estado a pagar una determinada cantidad de dinero a título de indemnización por el daño moral. Para ello, se tuvo presente que el derecho internacional de los derechos humanos prohíbe la prescripción, la posibilidad de amnistía, como también la consagración de excluyentes de responsabilidad que puedan impedir la investigación de los derechos esenciales tales como la tortura, las ejecuciones sumarias, desapariciones forzadas (Considerandos primero al cuarto de la Sentencia de la Excelentísima Corte Suprema. Considerando décimo y undécimo de la Ilustrísima Corte de Apelaciones de Santiago) ${ }^{74}$.

\footnotetext{
CHILE. Excelentísimo Tribunal Constitucional. Rol N² 2.615-14, Sentencia de 30 de octubre de 2014.

CHILE. Ilustrísima Corte de Apelaciones de Santiago. Rol No 21.223-2015, Sentencia de 30 de abril de 2015. Protección.

CHILE. Excelentísima Corte Suprema. Rol No 6.608-2015, Sentencia de 30 de julio de 2015.

3 CHILE, Ilustrísima Corte de Apelaciones de Santiago. Rol No 1.113-2012, Criminal, Sentencia de 22 de enero de 2014.

74 CHILE. Excelentísima Corte Suprema. Rol No 4.300-2014, Sentencia de 09 de septiembre de 2014.
} 


\section{Conclusiones}

Ya se ha hecho el recorrido, y, es preciso recordar el objetivo general, al preguntarse si son parte del bloque de constitucionalidad los principales tratados internacionales sobre derechos humanos de la ONU en el Estado de Chile. En efecto, la respuesta es un sí categórico. Ello, según como se ha respaldado con el desarrollo de los objetivos específicos del presente texto.

En primer lugar, desde el punto de vista de la doctrina (más ius naturalista por cierto), los tratados deben aplicarse porque contienen normas que reconocen derechos esenciales que emanan de la naturaleza humana, como también IUS COGENS en la materia.

En segundo lugar, desde el punto del derecho internacional convencional, los tratados son vinculantes de acuerdo con lo dispuesto en la Convención de Viena sobre Derechos de los Tratados, aplicando el principio de pacta sunt servanda y la buena fe de los tratados. Si Chile ha ratificado la Convención de Viena y los tratados internacionales de la ONU estudiados, estos son parte del bloque de constitucionalidad indiscutiblemente desde que han sido ratificados por Chile.

En tercer lugar, desde el punto del derecho constitucional, para el caso chileno en concreto, en aplicación del artículo 5 inciso segundo los tratados son parte del bloque de constitucionalidad desde que son ratificados por Chile, se encuentren vigentes y versen sobre derechos esenciales que emanan de la naturaleza humana. Así, se estudiaron aquellos requisitos: es evidente que sólo por el título y contenido que todos los tratados revisados son sobre derechos humanos, ergo, están dentro de la categoría; todos han sido ratificados por Chile, en distintas épocas, inclusive habiendo años de diferencia entre la ratificación y posterior publicación (pero esto último, la publicación es sólo una formalidad y no un requisito constitucional de aplicabilidad); $y$, todos tienen actual vigencia internacional como ha reflejado según la normativa e información dispuesta por Naciones Unidas.

En cuarto lugar, el texto positivo ha llegado a tribunales de justicia, en particular a los máximos tribunales, por lo que ha quedado comprobado que los tratados estudiados son parte del bloque de constitucionalidad también en la práctica, en la realidad de los casos judiciales. Un asunto no menor, pues como se revisaba en el trabajo, inclusive con la misma o similar normativa los tribunales de los años 80-90 se excusaban de aplicarlos por no haber ciertos requisitos de formalidad (como la publicación) o por ausencia de norma positiva que desarrolle su implementación en el ordenamiento jurídico interno.

En definitiva, la aseveración es positiva, puesto que, con la incorporación de los principales tratados internacionales sobre derechos humanos al bloque de constitucionalidad en Chile, se abre un abanico de derechos fundamentales para los habitantes de la Nación. Sí están en el texto positivo es un aporte, pero sí además se aplican en tribunales de justicia es un avance también en el fortalecimiento del Estado de Derecho chileno.

\section{Referencias}

BRITO CRUZ, Haroldo. Cuenta pública presidencia Corte Suprema 2018. Discurso del Presidente de la Corte Suprema señor Haroldo Brito Cruz. 2018. Disponible en: http://www.diariooficial.interior.gob.cl/publicaciones/2018/04/06/42025/01/1370510.pdf. Acceso en: 26 enero 2019

CHILE. Constitución Política de la República de Chile, última versión de 16 de junio de 2018. Disponible en https://www.leychile.cl/Navegar?idNorma=242302. Acceso en: 22 abr. 2019.

CHILE. Excelentísima Corte Suprem. Rol No 6.608-2015, Sentencia de 30 de julio de 2015. 
CHILE. Excelentísima Corte Suprema.

CHILE. Excelentísima Corte Suprema. Rol No 2.289-2015, Sentencia de 29 de marzo de 2016.

CHILE. Excelentísima Corte Suprema. Rol No 3.880-2012, Sentencia de 28 de mayo de 2012.

CHILE. Excelentísima Corte Suprema. Rol N 4.300-2014, Sentencia de 09 de septiembre de 2014.

CHILE. Excelentísima Corte Suprema. Rol No 8.891-2014, Sentencia de 15 de enero de 2015.

CHILE. Excelentísima Corte Suprema. Rol No3.015-2013, Sentencia de 05 de agosto de 2013.

CHILE. Excelentísimo Tribunal Constitucional. Rol No 2.231-2012, Sentencia de 01 abril de 2013.

CHILE. Excelentísimo Tribunal Constitucional. Rol No 2.615-14, Sentencia de 30 de octubre de 2014.

CHILE. Ilustrísima Corte de Apelaciones de Chillán. Rol No 12-2014, Reforma Laboral, Sentencia de 24 de marzo de 2014.

CHILE. Ilustrísima Corte de Apelaciones de Santiago. Rol No 1.969-2014, Civil, Sentencia de 26 de diciembre de 2014.

CHILE. Ilustrísima Corte de Apelaciones de Santiago. Rol N 41.989-2012, Protección, Sentencia de 01 abril de 2013.

CHILE. Ilustrísima Corte de Apelaciones de Santiago. Rol No 6.891-2013, Civil, Sentencia de 10 de diciembre de 2014.

CHILE. Ilustrísima Corte de Apelaciones de Santiago. Rol No 1.113-2012, Criminal, Sentencia de 22 de enero de 2014.

CHILE. Ilustrísima Corte de Apelaciones de Santiago. Rol No 2.678-2012 (Acumulado Rol 3.039-2012), Protección, Sentencia de 26 de abril de 2012.

CHILE. Ilustrísima Corte de Apelaciones de Santiago. Rol N² 21.223-2015, Protección, Sentencia de 30 de abril de 2015.

CHILE. Juzgado de Letras del Trabajo de Chillán. RIT O-224-2013, Sentencia de 08 de enero de 2014.

CHILE. Ley de reforma constitucional $N^{\circ}$ 18.825, de 17 de agosto de 1989. Disponible en: http://www.leychile. cl/Navegar/scripts/obtienearchivo?id=recursoslegales/10221.3/44169/2/HLArt5CPR.pdf. Acceso en: 22 abr. 2019.

CHILE. Ley $N^{\circ}$ 20.609, de 24 de julio de 2012, Establece medidas contra la discriminación. Acceso en: https:/ / www.leychile.cl/Navegar?idNorma=1042092. Disponible em: 22 abr. 2019.

CHILE. Ministerio de Relaciones Exteriores. Décimo Noveno Juzgado Civil de Santiago, Rol No C-24.8682009, Sentencia de 16 de enero de 2014.

CHILE. Ministerio de Relaciones Exteriores. Decreto Supremo 1562. Retira la reserva formulada al articulo 30, parrafo 1, de la convencion contra la tortura y otros tratos o penas crueles, inhumanos o degradantes. Publicado el 23 de diciembre de 1999.

CHILE. Ministerio de Relaciones Exteriores. Decreto Supremo 201. Promulga la convención de las naciones unidas sobre los derechos de las personas con discapacidad y su protocolo facultativo. Publicado el 17 de septiembre de 2008.

CHILE. Ministerio de Relaciones Exteriores. Decreto Supremo 280. Promulga la convención internacional para la protección de todas las personas contra las desapariciones forzadas. Publicado el 16 de abril de 2011.

CHILE. Ministerio de Relaciones Exteriores. Decreto Supremo 29. Promulga la enmienda al parrafo 2 del articulo 43 de la convencion sobre los derechos del niño. Publicado el 30 de abril de 2004. 
CHILE. Ministerio de Relaciones Exteriores. Decreto Supremo 326. Promulga el pacto internacional de derechos economicos, sociales y culturales, adoptado por la asamblea general de la organizacion de las naciones unidas el 19 de diciembre de 1966, suscrito por chile el 16 de septiembre de 1969. Publicado el 27 de mayo de 1989.

CHILE. Ministerio de Relaciones Exteriores. Decreto Supremo 381. Promulga la convencion sobre el derecho de los tratados y su anexo, suscrita por el gobierno de chile en viena, el 23 de mayo de 1969. Publicado el 22 de junio de 1981.

CHILE. Ministerio de Relaciones Exteriores. Decreto Supremo 39. Retira las reservas formuladas a la convencion contra la tortura y otros tratos o penas cruele, inhumanos o degradantes, adoptada por la asamblea general de la organizacion de las naciones unidas el 10 de diciembre de 1984. Publicado el 13 de marzo de 1991.

CHILE. Ministerio de Relaciones Exteriores. Decreto Supremo 747. Aprueba convención internacional sobre “eliminación de todas las formas de discriminación racial. Publicado el 12 de noviembre de 1971.

CHILE. Ministerio de Relaciones Exteriores. Decreto Supremo 778. Promulga el pacto internacional de derechos civiles y politicos adoptado por la asamblea general de la organizacion de las naciones unidas por resolucion $\mathrm{n}^{\circ} 2.200$, el 16 de diciembre de 1966 y suscrito por chile en esa misma fecha. Publicado el 29 de abril de 1989.

CHILE. Ministerio de Relaciones Exteriores. Decreto Supremo 789. Promulga la convencion sobre la eliminacion de todas las formas de discriminacion contra la mujer, adoptada por la asamblea general de las naciones unidas el 18 de diciembre de 1979. Publicado el 09 de diciembre de 1989.

CHILE. Ministerio de Relaciones Exteriores. Decreto Supremo 808. Promulga la convencion contra la tortura y otros tratos o penas crueles, inhumanos o degradantes, adoptada por la asamblea general de la organizacion de las naciones unidas mediante resolucion 39/46, de fecha 10 de diciembre de 1984. Publicado el 26 de noviembre de 1988.

CHILE. Ministerio de Relaciones Exteriores. Decreto Supremo 830. Publicado el 27 de septiembre de 1990.

CHILE. Ministerio de Relaciones Exteriores. Decreto Supremo 84. Promulga la convencion internacional sobre la proteccion de los derechos de todos los trabajadores migratorios y de sus familiares. Publicado el 08 de junio de 2005.

CHILE. Vigésimo quinto Juzgado Civil de Santiago. Rol No C-31.513-2009, Sentencia de 22 de julio de 2009.

CUMPLIDO CERECEDA, Francisco. La reforma constitucional de 1989 al inciso $2^{\circ}$ del artículo $5^{\circ}$ de la Constitución: sentido y alcance de la reforma. Doctrina y Jurisprudencia. Ius et Praxis, Talca, Chile, v. 9. n. 1. p. 365-374. 2003.

DÍAZ TOLOSA, Regina Ingrid. Aplicación judicial en Chile del "ius cogens" como manifestación de la internacionalización del Derecho interno en materia de protección de la dignidad humana. Revista de Derecho de la Pontificia Universidad Católica de Valparaíso, Valparaíso, Chile, n. 40. p. 393-417.

GOZAÍNI, Osvaldo. Derecho Procesal Transnacional: Los procedimientos en la Comisión y ante la Corte Interamericana de Derechos Humanos. México: Tirant lo Blanch, 2014.

IRTI, Natalino. La edad de la descodificación. España: J. M. Bosch Editor, 1992.

MARTÍN-RETORTILLO BAQUER, Lorenzo. Una visión de la tutela judicial a partir de la jurisprudencia de la Corte Interamericana y del Tribunal Europeo de Derechos Humanos. En: FERRER MAC GREGOR, Eduardo; HERRERA GARCÍA, Alfonso (coord.). Diálogo jurisprudencial en derechos humanos: entre Tribunales Constitucionales y Cortes Internacionales. 2013. p. 1217-1260. (In memoriam Jorge Carpizo, generador incansable de diálogos). 
MORALES MORALES, Alejandra Virginia; ODIMBA ON'ETAMBALAKO WETSHOKONDA, Jean Cadet. La incorporación del concepto del bloque de constitucionalidad en matéria de derechos humanos en México. Prolegómenos. Derechos y Valores, Bogotá, v. 12, n. 27, p. 135-14, enero-jun. 2011.

NACIONES UNIDAS. Convención contra la Tortura y Otros Tratos o Penas Crueles, Inhumanos o Degradantes. Resolución 39/46, de 10 de diciembre de 1984. Disponible en: https://treaties.un.org/doc/Treaties/1987/06/19870626\%2002-38\%20AM/Ch_IV_9p.pdf. Acceso en: 22 abr. 2019.

NACIONES UNIDAS. Convención de Viena sobre el Derecho de los Tratados, Resolución A/CONF.39/27, de 23 de mayo de 1969. Disponible en: https://treaties.un.org/doc/Treaties/1980/01/19800127\%20 00-52\%20AM/Ch_XXIII_01.pdf. Acceso en: 22 abr. 2019.

NACIONES UNIDAS. Convención internacional para la protección de todas las personas contra las desapariciones forzadas. Resolución A/RES/61/177, de 20 de diciembre de 2006. Disponible en: https://treaties.un.org/doc/ Publication/CTC/Ch_IV_16.pdf Acceso en: 22 abr. 2019.

NACIONES UNIDAS. Convención Internacional sobre la Eliminación de todas las Formas de Discriminación Racial. Resolución 2106 A (XX), de 21 de diciembre de 1965. Disponible en: https://treaties.un.org/doc/ source/docs/A_RES_2106-Eng.pdf. Acceso en: 22 abr. 2019.

NACIONES UNIDAS. Convención internacional sobre la protección de los derechos de todos los trabajadores migratorios y de sus familiares. Resolución 45/158, de 18 de diciembre de 1990. Disponible en: https:// treaties.un.org/doc/Treaties/1990/12/19901218\%2008-12\%20AM/Ch_IV_13p.pdf. Acceso en: 22 abr. 2019.

NACIONES UNIDAS. Convención sobre la eliminación de todas las formas de discriminación contra la mujer. Resolución 34/180, de 18 de diciembre de 1979. Disponible en: https://treaties.un.org/doc/Treaties/1981/09/19810903\%2005-18\%20AM/Ch_IV_8p.pdf. Acceso en: 22 abr. 2019.

NACIONES UNIDAS. Convención sobre los derechos de las personas con discapacidad. Resolución A/RES/61/106, de 13 de diciembre de 2006. Disponible en: https:/ / treaties.un.org/doc/Publication/CTC/Ch_IV_15.pdf Acceso en: 22 abr. 2019.

NACIONES UNIDAS. Convención sobre los Derechos del Niño. Resolución 44/25, de 20 de noviembre de 1989. Disponible en: https://treaties.un.org/doc/Treaties/1990/09/19900902\%2003-14\%20AM/Ch_ IV_11p.pdf. Acceso en: 22 abr. 2019.

NACIONES UNIDAS. Historia de la redacción de la Declaración Universal de Derechos Humanos. Disponible en: http://www.un.org/es/documents/udhr/history.shtml. Acceso en: 25 enero 2019.

NACIONES UNIDAS. Pacto Internacional de Derechos Civiles y Políticos. Resolución 2200 A (XXI), de 16 de diciembre de 1966. Disponible en https://treaties.un.org/doc/Treaties/1976/03/19760323\%2006-17\%20 AM/Ch_IV_04.pdf. Acceso en: 22 abr. 2019.

NACIONES UNIDAS. Pacto Internacional de Derechos Económicos, Sociales y Culturales. Resolución 2200 A (XXI), de 16 de diciembre de 1966. Disponible en: https://treaties.un.org/doc/Treaties/1976/01/19760103\%20 09-57\%20PM/Ch_IV_03.pdf. Acceso en: 22 abr. 2019.

NACIONES UNIDAS. Status of Treaties. Chapter IV. Human Rights. 11. Convention on the Rights of the Child. Disponible en: https://treaties.un.org/doc/Publication/MTDSG/Volume\%20I/Chapter\%20IV/ IV-11.en.pdf. Acceso en: 22 abr. 2019.

NACIONES UNIDAS. Status of Treaties. Chapter IV. Human Rights. 13. International Convention on the Protection of the Rights of All Migrant Workers and Members of their Families. Disponible en: https:/ / treaties.un.org/ doc/Publication/MTDSG/Volume\%20I/Chapter\%20IV/IV-13.en.pdf. Acceso en: 22 abr. 2019.

NACIONES UNIDAS. Status of Treaties. Chapter IV. Human Rights. 15. Convention on the Rights of Persons 
with Disabilities. Disponible en: https://treaties.un.org/doc/Publication/MTDSG/Volume\%20I/Chapter\%20IV/IV-15.en.pdf. Acceso en: 22 abr. 2019.

NACIONES UNIDAS. Status of Treaties. Chapter IV. Human Rights. 16. International Convention for the Protection of All Persons from Enforced Disappearance. Disponible en: https://treaties.un.org/doc/Publication/ MTDSG/Volume\%20I/Chapter\%20IV/IV-16.en.pdf Acceso en: 22 abr. 2019.

NACIONES UNIDAS. Status of Treaties. Chapter IV. Human Rights. 2. International Convention on the Elimination of All Forms of Racial Discrimination. Disponible en: https://treaties.un.org/doc/Publication/ MTDSG/Volume\%20I/Chapter\%20IV/IV-2.en.pdf. Acceso en: 22 abr. 2019.

NACIONES UNIDAS. Status of Treaties. Chapter IV. Human Rights. 3. International Covenant on Economic, Social and Cultural Rights. Disponible en: https://treaties.un.org/doc/Publication/MTDSG/Volume\%20I/ Chapter\%20IV/IV-3.en.pdf. Acceso en: 22 abr. 2019

NACIONES UNIDAS. Status of Treaties. Chapter IV. Human Rights. 4. International Covenant on Civil and Political Rights. Disponible en: https://treaties.un.org/doc/Publication/MTDSG/Volume\%20I/Chapter\%20 IV/IV-4.en.pdf. Acceso en Disponible en: 22 abr. 2019.

NACIONES UNIDAS. Status of Treaties. Chapter IV. Human Rights. 8. Convention on the Elimination of All Forms of Discrimination against Women. Disponible en: https://treaties.un.org/doc/Publication/MTDSG/ Volume\%20I/Chapter\%20IV/IV-8.en.pdf. Acceso en: 22 abr. 2019.

NACIONES UNIDAS. Status of Treaties. Chapter IV. Human Rights. 9. Convention against Torture and Other Cruel, Inbuman or Degrading Treatment or Punishment. Disponible en: https://treaties.un.org/doc/Publication/ MTDSG/Volume\%20I/Chapter\%20IV/IV-9.en.pdf. Acceso en: 22 abr. 2019.

NACIONES UNIDAS. Status of Treaties. Chapter XXIII. Law of Treaties. 1. Vienna Convention on the Law of Treaties. Disponible en: https://treaties.un.org/doc/Publication/MTDSG/Volume $\% 20 I I / C h a p t e r \% 20$ XXIII/XXIII-1.en.pdf. Acceso en: 22 abr. 2019.

NOGUEIRA ALCALÁ, Humberto. Los derechos esenciales o humanos contenidos en los tratados internacionales y su ubicación en el ordenamiento jurídico nacional: doctrina y jurisprudencia. Ius et Praxis, Talca, Chile, v. 9, n. 1, p. 403-466, 2003. 
Para publicar na revista Brasileira de Políticas Públicas, acesse o endereço eletrônico www.rbpp.uniceub.br

Observe as normas de publicação, para facilitar e agilizar o trabalho de edição. 